\title{
Winter chemical partitioning of metals bound to atmospheric fine particles in Dongguan, China, and its health risk assessment
}

\author{
Lin Huang ${ }^{1,2}$ (I) $\cdot$ Yun-He Bai ${ }^{1,2} \cdot$ Rui-Yue Ma ${ }^{1,2} \cdot$ Ze-Ming Zhuo ${ }^{1,2} \cdot$ Ling Chen $^{3}$
}

Received: 25 July 2018 / Accepted: 26 March 2019 / Published online: 9 April 2019

(C) The Author(s) 2019

\begin{abstract}
To analyze the relationship between nanoparticles and the chemical forms in an urban atmospheric environment, metallic particles with different diameters were collected using a nanoparticle sampling system and analyzed for chemical and morphological characteristics, bioactivity, and the risk of carcinogenic and non-carcinogenic effects. The source of the atmospheric particles was analyzed based on the enrichment factor method, and the carcinogenicity of the atmospheric particles was analyzed using the health risk model. The partition contents of metals extractable by a weak acid, including $\mathrm{As}, \mathrm{Ca}, \mathrm{Cd}, \mathrm{Cs}, \mathrm{Pb}, \mathrm{Sr}$, and $\mathrm{Zn}$, were in a range of $32.17-71.4 \%$, with an average value of $47.07 \%$. The content of oxides and reducible metals of all of the elements was generally low. Potassium was distributed mainly in the residual and weak-acid-extractable fractions. Barium had a high proportion of the oxidation state. Each fraction of $\mathrm{Zn}$ was basically the same, while the content of the weak-acid-extractable fraction was slightly higher. We found bio-access potential to be positively correlated with a high proportion of the weak acid extracts such as $\mathrm{Mg}, \mathrm{Sr}$, and $\mathrm{Zn}$. We also found there to be a large weak-acid-extractable fraction (F1) and residual fraction (F4) and relatively enriched elements and strongly enriched elements, which means F1 and F4 may be the cause of enrichment. The hazard index (HI) and the total cancer risk (TCR) were far beyond the safety threshold when the diameter of the particle was in the range of $0.1-0.5 \mu \mathrm{m}$, indicating that the residents in Dongguan city were experiencing obvious non-carcinogenic and carcinogenic risks.
\end{abstract}

Keywords Atmospheric particulates $\cdot$ Chemical forms $\cdot$ Exposure reaction $\cdot$ Health risks $\cdot$ Metal elements $\cdot$ Meteorological factors $\cdot \mathrm{PM}_{2.5}$

\section{Introduction}

Atmospheric pollution is a serious global environmental problem. The main sources of atmospheric particulate matter, which may seriously damage the atmosphere, are automobile exhaust, industrial emissions, coal combustion, and road dust. Particles with different diameters have different compositions.

Responsible editor: Philippe Garrigues

Lin Huang

linhuangsz@163.com

1 School of Environment and Civil Engineering, Dongguan University of Technology, Dongguan 523808, China

2 Air Pollution Complex of Key Laboratory of Dongguan, Dongguan 523000, China

3 The Second Base of Science Research Institute of Metrology in Dongguan City, Dongguan 523000, China
Their surface contains adsorbed toxic and carcinogenic heavy metals and organic compounds, which represent a great hazard to human health. When the size of the particles is smaller than $2.5 \mu \mathrm{m}$, inhalation of these fine particles into the human body can lead to lung disease, heart disease, and arteriosclerosis (Ballester 2001; Donaldson et al. 2002; Lewis et al. 2005; Ostro et al. 2006; Samoli et al. 2005). Many epidemiological studies have shown that the lung cancer mortality rate increased by $8 \%$ and the mortality rate caused by cardiovascular disease increased by $6 \%$ when the concentration of $\mathrm{PM}_{2.5}$ increased to $10 \mathrm{~g} / \mathrm{m}^{3}$ (Pope III et al. 2002). Compared with atmospheric coarse particles, $\mathrm{PM}_{2.5}$ has a proportionally larger surface to absorb pollutants from the atmosphere. The human body can absorb fine particles by respiration and accumulate heavy metals ( $\mathrm{Hu}$ et al. 2012; Li et al. 2013b). In addition, the metal particles absorbed by atmospheric particle material (PM) can travel far and be deposited in the soil, bodies of water, and on leaves of plants through wet and dry sedimentation, thereby posing an environmental risk ( $\mathrm{Li}$ 
et al. 2013b). Therefore, it is important to execute a human health assessment to study the harmfulness of air particulates with particles of different diameters.

The chemical composition of PM is crucial to its toxicity, as well as the particle concentration and size distribution (Xie et al. 2012). When assessing the potential environmental and health risks, the key is to know not only the amount of particle-bound metals but also their chemical partitioning, which determines the behavior of environmental metals (Betha et al. 2014). It is largely accepted that the chemical forms of metals determine their potential risks to human and environmental health through the processes of mobility and bioavailability (Pérez et al. 2008; Schleicher et al. 2011). Extraction methods that are run sequentially have been widely used to describe the chemical fractions of metals in environmental samples, including soil, river, and atmospheric particles under natural conditions (Arain et al. 2008; Davidson et al. 2006; Li et al. 2013a; Schleicher et al. 2011; Yuan et al. 2011). The human body is able to absorb and mobilize the weak-acid-extractable metal fractions (F1) in body fluids, producing toxicity (Mukhtar and Limbeck 2013). Components of metals that are bound to organic matter and oxidizable or sulfidic metals (F3) can become mobile under strong oxidization and can be converted or changed to the weak-acid-extractable (F1) or oxide fraction (F2). Toxicity of the residual fraction (F4) to animals and plants and its bioavailability are very low. Many studies have examined the relationship between meteorological factors and the chemical composition of PM, and there are some differences in the correlation between the particle concentrations and meteorology. In this study, we briefly discuss the correlation between the different metals and atmospheric meteorological factors.

Dongguan, China, has severe air pollution because of its rapid development. Therefore, local residents may face health risks, and it is necessary to establish measures for the management and control of airborne metals. In this study, we used certain assumptions for the health risk assessment that may introduce uncertainty in the evaluation model, reference data, toxic exposure default parameters, and population characteristics. Despite some uncertainty, the model has proven to be a useful tool for assessing risks to human health caused by toxic metal exposure in a city environment ( $\mathrm{Li}$ et al. 2017).

There are few studies on the particle size distribution and health risk assessment in the existing research on heavy metals in Dongguan's atmospheric particulate matter. The biological toxicity of some heavy metals in different particle sizes has also been rarely reported. Thus, the main objectives of this study were as follows: (1) to analyze the concentration of elements ( $\mathrm{Al}, \mathrm{As}, \mathrm{Ba}, \mathrm{Ca}, \mathrm{Cd}, \mathrm{Cr}, \mathrm{Co}, \mathrm{Cu}, \mathrm{Fe}, \mathrm{K}, \mathrm{Mg}, \mathrm{Mn}$, $\mathrm{Pb}, \mathrm{Sr}, \mathrm{V}$, and $\mathrm{Zn}$ ) and the enrichment factors of metals in the atmospheric fine particles during the winter season of 20162017, (2) to analyze the chemical partitioning of metals bound to fine particles and determine the bio-accessibility of metals in $\mathrm{PM}_{2.5}$, and (3) to evaluate the carcinogenic and noncarcinogenic health risks via inhalation of toxic metals found in the atmospheric fine particles.

\section{Methods and materials}

\section{Sampling}

The city of Dongguan is located at $22^{\circ} 39^{\prime}-23^{\circ} 09^{\prime} \mathrm{N} 13^{\circ} 31^{\prime}-$ $114^{\circ} 15^{\prime} \mathrm{E}$, and is situated in the south of the province of Guangdong. The city is adjacent to the Pearl River Delta, and it is an important industrialized area in China. The atmospheric quality of the study region is influenced by the industrial emission of pollutants, human activities, and suburban traffic. The $\mathrm{PM}_{2.5}$ samples were collected from the Second Base of Science Research Institute of Metrology in Dongguan. Further details are illustrated in Fig. 1.

The $\mathrm{PM}_{2.5}$ samples were obtained using a six-level sampling apparatus, obtained from Westech Environmental, Inc. (Model M372106, flow rate $28.3 \mathrm{~L} / \mathrm{min}$, UK), that was used to collect particles with different diameters. The particle diameters were divided into six classes: I-VI $(<0.1 \mu \mathrm{m}, 0.1-$ $0.5 \mu \mathrm{m}, 0.5-1 \mu \mathrm{m}, 1-2.5 \mu \mathrm{m}$, and $2.5-10 \mu \mathrm{m},>10 \mu \mathrm{m}$, respectively). Daytime and nighttime (8:00-18:00 and 19:00$7: 00$, respectively) sampling were implemented during the winter season from January 1 to 30, February 1 to 20, and March 1 to 29, 2016. There were a few days of fog and haze in this period. The air quality monitoring station near the sampling point also recorded the weather data per hour and the concentration of the air pollutants per hour. Before sampling, the filter membrane was conditioned in a desiccator for $48 \mathrm{~h}$ at $25{ }^{\circ} \mathrm{C}$ with a $60 \%$ relative humidity, and it was weighed. After sampling the aerosols, the filter membranes were conditioned using a desiccator for $48 \mathrm{~h}$, and then they were weighed to determine the $\mathrm{PM}_{2.5}$ mass. A total of 42 samples were collected from January to March.

\section{Sequential extraction procedure}

Four fractions of particulate-bound metals were obtained by the following four-step BCR (Community Bureau of Reference) procedure of sequential extraction: (1) weak-acid-extractable metals (F1); (2) reducible metals and oxides (F2); (3) organic matter-bound metals, sulfidic, and oxidizable metals (F3); and (4) residual metals (F4). Table 1 summarizes each of the steps. The modified BCR method was used to analyze the fractions of elements; $3 / 4$ of the sample filter membrane, by area, was used in the test. In each extraction step, the samples were centrifuged (Shanghai Anting, TDL 500DR, China) for $40 \mathrm{~min}$ at $7500 \mathrm{rpm}$, and the supernatants were transferred to volumetric flasks. We used the filter to perform another extraction; we then centrifuged the extracted sample, and the supernatant was poured into the 
Fig. 1 Meteorological data $(\mathrm{P}$, pressure; $\mathrm{RH}$, relative humidity; $\mathrm{T}$, temperature; WS, wind speed) and concentration of $\mathrm{PM}_{2.5}$ measured during sampling

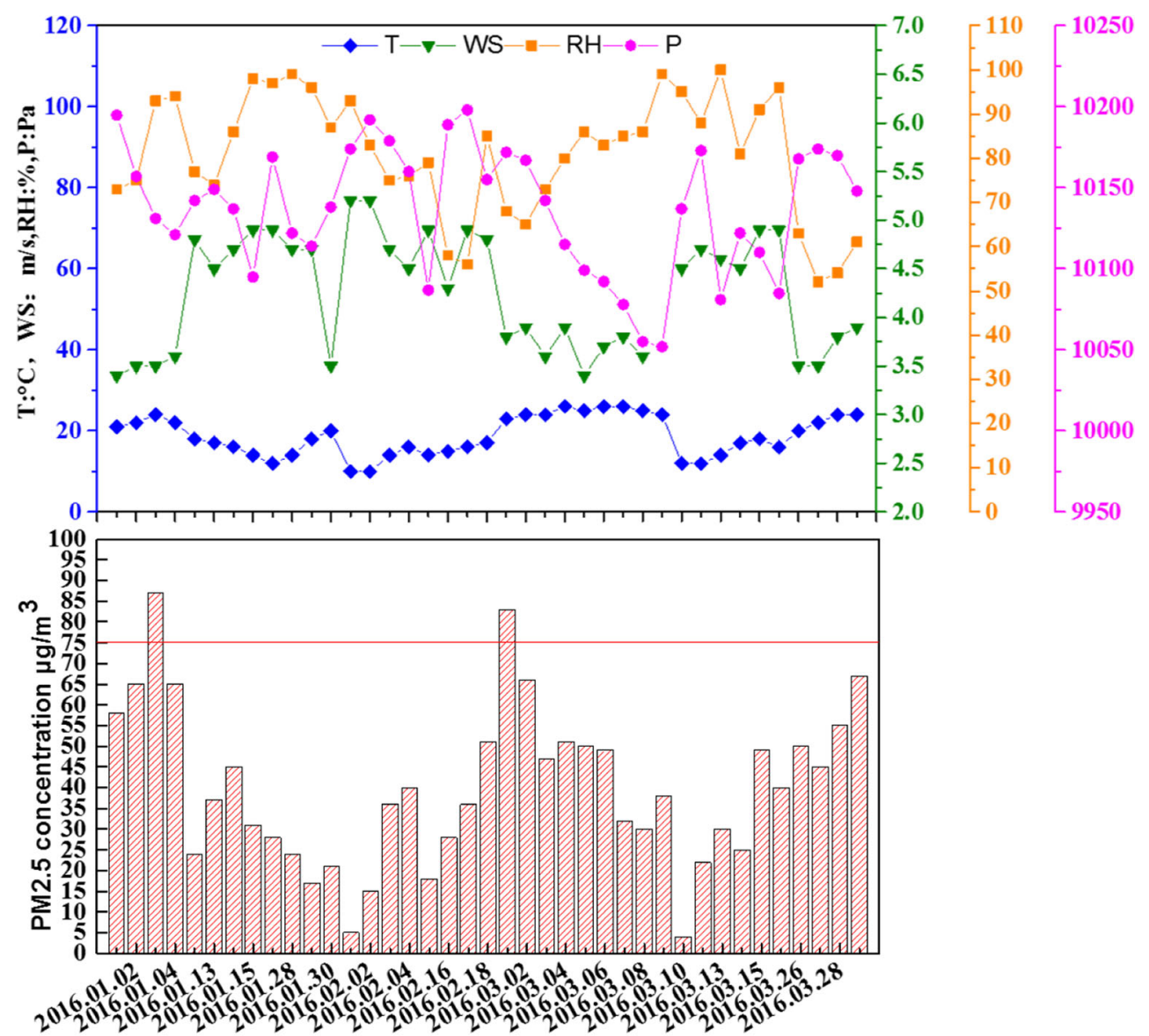

date washing filter flask. The mixed supernatant was heated and concentrated to $1-2 \mathrm{~mL}$ and then diluted with $2 \%$ nitric acid (Shenzhen Chemical Co., Ltd., China) for analysis. The simultaneous analysis of six blank filters was conducted during the sequential BCR extraction procedure, and the metal concentration of each sample was adjusted by the subtraction of the blank average concentration.

\section{Analyses of the concentrations of the elements}

The concentrations of the metals ( $\mathrm{Al}, \mathrm{As}, \mathrm{Ba}, \mathrm{Cu}, \mathrm{Ca}, \mathrm{Cd}, \mathrm{Cr}$, $\mathrm{Co}, \mathrm{K}, \mathrm{Fe}, \mathrm{Mg}, \mathrm{Mn}, \mathrm{Pb}, \mathrm{Ni}, \mathrm{Sr}, \mathrm{V}$, and $\mathrm{Zn}$ ) in the components and their chemical partitioning were measured using an inductively coupled plasma atomic emission spectrometer (ICPAES, ICAP 7000, Thermo Fisher Scientific, USA) and

Table 1 Operating conditions and reagents used in the BCR

\begin{tabular}{|c|c|c|}
\hline Fraction & Reagents & Experimental setup \\
\hline F1 & $0.11 \mathrm{~mol} / \mathrm{L} \mathrm{CH} 3 \mathrm{COOH}$ & $\begin{array}{l}\text { 16-h agitation on a shaker at room temperature, } \\
\text { centrifugal separation for } 40 \mathrm{~min} \text { at } 7500 \mathrm{rpm} \times \mathrm{g} \text {; } \\
\text { the supernatant was separated from the residuals }\end{array}$ \\
\hline $\mathrm{F} 2$ & $0.1 \mathrm{~mol} / \mathrm{L} \mathrm{NH} \mathrm{NH}_{2} \mathrm{OH} \cdot \mathrm{HCl}$ at $\mathrm{pH} 2$ & $\begin{array}{l}\text { 6-h agitation on a shaker and the washing process of } \\
\text { insoluble matter was the same as before }\end{array}$ \\
\hline F3 & $30 \% \mathrm{H}_{2} \mathrm{O}_{2}, 1 \mathrm{~mol} / \mathrm{L} \mathrm{HAC}$ at $\mathrm{pH} 3$ & $\begin{array}{l}\text { Shaken for } 60 \mathrm{~min} \text { at room temperature, } 1 \mathrm{~h} \text { of heating in } \\
\text { a water bath at low temperature (lower than } 20^{\circ} \mathrm{C} \text { ), heated } \\
\text { until } 2 \mathrm{~mL} \text { of solution remained. The first steps were repeated. } \\
\text { The sample was agitated on a shaker for } 30 \text { min. } \\
\text { The supernatant was decanted from the residuals }\end{array}$ \\
\hline F4 & $\mathrm{HNO}_{3}, \mathrm{H}_{2} \mathrm{O}_{2}$ & $\begin{array}{l}\text { Shaken for } 30 \mathrm{~min} \text { at room temperature, dispelled in a } \\
\text { microwave instrument. The supernatant was decanted from the } \\
\text { residuals with a } 0.45-\mu \mathrm{m} \text { needle filter. }\end{array}$ \\
\hline
\end{tabular}


inductively coupled plasma-mass spectrometer (ICP-MS, Agilent 7900, USA). The descriptive statistical correlation analysis of the experimental data was conducted using SPSS 21 software (IBM, USA). A mixed solution of $2 \% \mathrm{HNO}_{3}$ and

${ }^{115} \mathrm{In}$ at a concentration of $20 \mathrm{mg} / \mathrm{L}$ was utilized as the internal standard to measure the drift during the instrument calibration. Before the test, the ICP-MS needed to be calibrated for the analog signal/pulse ratios, dynamic linear range, and P/A factor. The calibration can expand the working curve and reduce the measurement time for the quantitative analysis. The internal recovery of each metal is the ratio between the sum of the concentrations of the 4 chemical fractions and the total metal concentration. The calculation of the recovery was as follows:

Recovery $(\%)=\frac{F 1+F 2+F 3+F 4}{T C} \times 100 \%$

where F1-F4 represent the concentrations of the elements extracted from each fraction, whereas TC refers to their summed concentration. In general, recovery rates of the studied elements ranged from 86 to $112 \%$, showing that the total content of these 4 fractions and the total concentration are in good agreement, reliable, and repeatable. In this study, the heavy metal recovery rate ranged from 87 to $101 \%$, indicating that our experimental results are consistent with the references.

\section{Enrichment factors}

The enrichment factor (EF) — a test of elements based on the specification of the conservative reference value (Chen et al. 2008)_was utilized to identify the possible origins of the elements in atmospheric fine particles. The enrichment factor method was utilized to indicate the degree of enrichment of the elements in the atmospheric PM and evaluate the particulate matter in natural and manmade sources. The enrichment factor was calculated as follows:

$E F_{i}=\frac{\left(C_{i} / C_{n}\right)_{\text {sample }}}{\left(C_{i} / C_{n}\right)_{\text {reference }}}$

$C_{\mathrm{i}}$ concentrations of i elements,

$C_{\mathrm{n}}$ reference element concentration.

The enrichment factor method is a calculation of double normalization. It can eliminate the influence of the uncertain factors caused by atmospheric particulate sampling, analysis, wind speed, wind direction, and the distance from a variety of sources of pollution. It is thus more reliable and accurate than a direct comparison of the element concentrations (Shao et al. 2006). Generally, the reference elements are selected from the Earth's crust in a region with few pollution sources and have a good chemical stability; thus, they provide a high accuracy of the analysis results of poorly volatile elements. Many studies used reference elements such as Fe, Al, Si, Ti, and Se. For the purposes of the present study, we chose the reference element $\mathrm{Al}$, and we used the values from the published Chinese values of background soil elements (CNEMC 1990).

The greater the EF value, the higher the enrichment. We divided the results of the EF analysis into 3 categories: the elements with EF $>10$ were mainly derived from anthropogenic pollution; the elements with $\mathrm{EF}<10$ originated from a natural source, mainly from soil background materials, and a low EF indicated that the target element was scarce. The elements with $\mathrm{EF}=10$ were a result of interactions between anthropogenic and natural sources (Yang et al. 2012). In addition, $10<\mathrm{EF}<100$ indicated that the element was relatively abundant, while the EF $>$ 100 indicated a typical abundance of the element in question.

\section{Assessment of the health risks of toxic metals found in the atmospheric fine particles}

The health risk assessment model of human exposure recommended by the US EPA is an important method in the field of heavy metal health risk research. We used the concepts of the average daily dose (ADD), carcinogenic risk (CR), and non-carcinogenic risk value (hazard quotient, HQ) proposed by the model and selected the exposure parameters of the specific population. Air pollutants enter the human body mainly through respiratory pathways. However, if we only consider the health risks caused by respiratory exposure and ignore the health risks caused by hand-mouth intake and skin contact, the calculated health risks will be less than the actual health risks. Therefore, 3 types of exposure were included in this study. The most commonly used exposure equation is the average daily dose (ADD). There are 3 main ways that atmospheric particles enter the bodies of humans: dermal contact $\left(D_{\mathrm{der}}, \mathrm{mg} \mathrm{kg}^{-1} \mathrm{day}^{-1}\right.$ ), ingestion ( $\mathrm{D}_{\mathrm{ing}}$, $\mathrm{mg} \mathrm{kg}{ }^{-1}$ day $^{-1}$ ), and inhalation $\left(D_{\text {inh }}, \mathrm{mg} \mathrm{kg}^{-1} \mathrm{day}^{-1}\right)$. The calculations for these values were as follows:

$\mathrm{ADD}_{\text {ing }}=\frac{C \times \operatorname{IngR} \times \mathrm{EF} \times \mathrm{ED} \times \mathrm{CF}}{\mathrm{BW} \times \mathrm{AT}}$

$\mathrm{ADD}_{\text {dermal }}=\frac{C \times \mathrm{SA} \times \mathrm{AF} \times \mathrm{ABS} \times \mathrm{EF} \times \mathrm{ED} \times \mathrm{CF}}{\mathrm{BW} \times \mathrm{AT}}$

$\mathrm{ADD}_{\text {inh }}=\frac{C \times \mathrm{InhR} \times \mathrm{EF} \times \mathrm{ED}}{\mathrm{PEF} \times \mathrm{BW} \times \mathrm{AT}}$

The risk characterization can be categorized into the carcinogenic risk assessment and assessment of the non- 
carcinogenic risk. The HQ represents the non-carcinogenic risk. The expression of the assessment of the carcinogenic risk was created using the following formulas:

$$
\begin{aligned}
& \mathrm{HQ}=\frac{\mathrm{ADD}}{\mathrm{RFD}} \\
& \mathrm{HI}=\sum_{i=1}^{n} \mathrm{HQ}_{i} \\
& \mathrm{CR}=\mathrm{ADD}_{\text {inhalation }} \times \mathrm{CSF}_{\text {inhalation }}
\end{aligned}
$$

where $C$ represents the concentration of the particulate matter, IngR is the intake rate of ingestion $(30 \mathrm{mg} /$ day for adults and $60 \mathrm{mg}$ /day for children), EF represents the frequency of exposure (180 days/year), and ED is the exposure duration (for children of 6 years and adults of 24 years). CF is the conversion coefficient $\left(10^{-6} \mathrm{~kg} / \mathrm{mg}\right)$. ATN represents the average time (non-carcinogens: ATN $=\mathrm{ED} \times 365$ days $\times 24 \mathrm{~h}$ per day; carcinogens: ATN $=70$ years $\times 365$ days per year $\times$ $24 \mathrm{~h}$ ). SA represents the parameter for the skin surface (the adult threshold is $5700 \mathrm{~cm}^{2}$ and the child threshold is $\left.2700 \mathrm{~cm}^{2}\right)$. AF is the adsorption coefficient of skin to soil $\left(0.07 \mathrm{mg} / \mathrm{cm}^{2}\right.$ for adults and $0.2 \mathrm{mg} / \mathrm{cm}^{2}$ for children). ABS is the skin absorptivity (0.001). InhR is the respiratory rate of inhalation $\left(7.63 \mathrm{~m}^{3} /\right.$ day for adults and $20 \mathrm{~m}^{3} /$ day for children). PEF is the emission factor $\left(1.36 \times 10^{9} \mathrm{~m}^{3} / \mathrm{kg}\right)$, RFD represents the reference dose $(\mathrm{mg} / \mathrm{kg} /$ day $)$, and the cancer slope factor $(\mathrm{mg} / \mathrm{kg} /$ day) is represented by CSF.

We measured the total concentration of $\mathrm{Cr}$. However, the US EPA lists Cr (VI) within group A (human carcinogens) and $\mathrm{Cr}$ (III) in group D (not classified as a human carcinogen). An assumption was made that the ratio of the concentration of $\mathrm{Cr}$ (VI) and Cr (III) ranges from 1 to 6, according to the US EPA (2011), and other researchers used this ratio to assess the health risk of $\mathrm{Cr}$ (VI) in $\mathrm{PM}_{2.5}$ (Hsu et al. 2016). For the purpose of the EC estimation in the present study, the $\mathrm{Cr}$ (VI) concentration was therefore assumed to be $1 / 7$ th of the Cr total concentration.

\section{Results and discussion}

\section{$\mathbf{P M}_{2.5}$ mass concentration}

The quality of air in Dongguan area was analyzed using the air quality index (AQI) and the National Ambient Air Quality Standards (NAAQS; GB3095-2012). The average concentration of $\mathrm{PM}_{2.5}$ was $40.1 \mathrm{~m} / \mathrm{m}^{3}$, with a range of $4-87 \mu \mathrm{g} / \mathrm{m}^{3}$, while the highest $\mathrm{PM}_{2.5}$ concentration, detected on January 3, was $87 \mu \mathrm{g} / \mathrm{m}^{3}$, which was 1.16 times the limit of the air quality standards. The relative humidity was $95 \%$ (the highest value measured), the temperature was $24{ }^{\circ} \mathrm{C}$, and the sampling speed of the wind was only $3.5 \mathrm{~m} / \mathrm{s}$.
On haze-fog (HF) days, the average wind speed was $3.65 \mathrm{~m} / \mathrm{s}$ (range $3.5-3.8 \mathrm{~m} / \mathrm{s}$ ) and the relative humidity was $80.5 \%$ (range $68 \%-93 \%$; Fig. 1). During the period of HF (January 3 to March 1), the average daily concentration of $\mathrm{PM}_{2.5}$ was $85 \mu \mathrm{g} / \mathrm{m}^{3}$ (range $83-87 \mu \mathrm{g} / \mathrm{m}^{3}$ ), which exceeded the 24 -h limit $\left(75 \mu \mathrm{g} / \mathrm{m}^{3}\right)$ specified by NAAQS and GB3095-2012 (Fig. 1). The high concentration of $\mathrm{PM}_{2.5}$ may be an indicator for HF quantification. On nonHF days, the average wind speed was $4.26 \mathrm{~m} / \mathrm{s}$ (range 3.4 $5.2 \mathrm{~m} / \mathrm{s}$ ) and the relative humidity was $81.03 \%$ (range 52 $100 \%)$.

\section{Total concentration of elements}

As shown in Table 2, $\mathrm{Zn}, \mathrm{Fe}, \mathrm{Al}, \mathrm{Ca}$, and $\mathrm{K}$ had high concentrations, while the concentrations of $\mathrm{Cd}, \mathrm{V}, \mathrm{Sr}$, and $\mathrm{Co}$ were lower. In general, the average concentrations of all of the elements were significantly elevated in winter, especially on the HF days. This result is mainly because the atmosphere during HF days is layered, stable, and conducive to air pollutant accumulation (Kang et al. 2013). We referred to the concentration limits set by NAAQS and WHO as standards in the metal concentration analysis, and we noted that both of them were applicable to the limit of the metal particle concentration (Li et al. 2013a). During the sampling period, the As total concentration exceeded the limit values of NAAQS $(6 \mathrm{ng} /$ $\left.\mathrm{m}^{3}\right)$ and WHO $\left(6.6 \mathrm{ng} / \mathrm{m}^{3}\right)$; the same was true for $\mathrm{Cd}$ (the limit value of both WHO and NAAQS is $5 \mathrm{ng} / \mathrm{m}^{3}$ ). However, the concentration of the sampled $\mathrm{Pb}$ reached one-half of the limit values of WHO and NAAQS for $\mathrm{Pb}\left(500 \mathrm{ng} / \mathrm{m}^{3}\right)$. NAAQS defines no limit values for $\mathrm{Ni}, \mathrm{Mn}$, and $\mathrm{V}$; however, the concentration of Ni exceeded the WHO guideline $\left(25 \mathrm{ng} / \mathrm{m}^{3}\right)$ by tenfold, and Mn exceeded twofold the WHO guideline $\left(150 \mathrm{ng} / \mathrm{m}^{3}\right)$ during the sampling period, which illustrates that the two metals may pose a certain risk to human health. The concentration of $\mathrm{V}$ was below the WHO limit values $\left(1000 \mathrm{ng} / \mathrm{m}^{3}\right)$, illustrating that $\mathrm{V}$ was relatively scarce in the atmosphere and did not represent a health risk.

Some of our conclusions are confirmed by the information shown in Table 3, indicating that there is a certain relationship between the concentrations of the metal elements and the meteorological factors. In this study, the concentrations of most elements (except $\mathrm{Mg}$ and $\mathrm{Zn}$ ) were negatively correlated with the temperature (the correlation coefficients range from 0.080 for $\mathrm{Ca}$ to -0.729 for $\mathrm{K}$ ); the reason for this correlation was that the airborne particles were in the low frequency range of the temperature inversion when the temperature was high. Even if the temperature inversion happened, the thickness of its inversion layer was low, the strength was weak, the boundary layer structure was unstable, and, under the effect of the diffusion and settlement, the concentration of the atmospheric particles decreased. However, the concentrations of other metals (except $\mathrm{Cu}$ and $\mathrm{Ca}$ ) were negatively correlated with 
Table 2 Metal enrichment factors and total concentrations in fine particulate matter with different diameters during the sampling period

\begin{tabular}{|c|c|c|c|c|c|c|}
\hline \multirow[t]{2}{*}{ Metal } & \multirow[t]{2}{*}{$\mathrm{TC}\left(\mathrm{ng} / \mathrm{m}^{3}\right)$} & \multicolumn{4}{|l|}{$\mathrm{EF}$} & \multirow{2}{*}{$\begin{array}{l}\text { The EF of } \mathrm{PM}_{2.5} \\
\text { Mean }\end{array}$} \\
\hline & & $\mathrm{d}<0.1$ & $0.1<\mathrm{d}<0.5$ & $0.5<\mathrm{d}<1$ & $1<\mathrm{d}<2.5$ & \\
\hline $\mathrm{Al}$ & $2350.00 \pm 80.00$ & / & / & I & / & / \\
\hline As & $75.80 \pm 2.53$ & $208.8 \pm 68.96$ & $141.6 \pm 44.06$ & $266.1 \pm 281.85$ & $112.19 \pm 82.13$ & $786.87 \pm 387.77$ \\
\hline $\mathrm{Ba}$ & $504.00 \pm 7.966$ & $18.6 \pm 8.03$ & $7.1 \pm 4.58$ & $12.1 \pm 5.56$ & $12.44 \pm 9.34$ & $52.61 \pm 14.48$ \\
\hline $\mathrm{Ca}$ & $3238.8 \pm 104.7$ & $5.1 \pm 3.19$ & $1.4 \pm 1.31$ & $3.4 \pm 1.67$ & $3.5 \pm 3.28$ & $13.17 \pm 9.03$ \\
\hline $\mathrm{Cd}$ & $7 \pm 0.5$ & $434.5 \pm 236.26$ & $486.13 \pm 173.02$ & $451.5 \pm 281.64$ & $444.5 \pm 605.31$ & $2180.22 \pm 1127.70$ \\
\hline Co & $35.65 \pm 1.48$ & $22.3 \pm 17.53$ & $503.7 \pm 502.02$ & $11.9 \pm 5.29$ & $15.03 \pm 10.80$ & $864.45 \pm 657.37$ \\
\hline $\mathrm{Cr}$ & $1748.3 \pm 126.3$ & $52.7 \pm 36.05$ & $2403.5 \pm 2488.84$ & $24.7 \pm 11.85$ & $36.1 \pm 33.37$ & $3973.62 \pm 3330.15$ \\
\hline $\mathrm{Cu}$ & $308.4 \pm 12.9$ & $142.69 \pm 71.00$ & $261.88 \pm 165.94$ & $119.09 \pm 83.61$ & $88.79 \pm 67.41$ & $612.4543908 \pm 65.64$ \\
\hline $\mathrm{Fe}$ & $2797.9 \pm 75$ & $3.16 \pm 1.55$ & $8.7 \pm 14.11$ & $2.6 \pm 0.97$ & $3.3 \pm 1.77$ & $768.09 \pm 203.60$ \\
\hline K & $5970 . \pm 216$ & $6.5 \pm 3.61$ & $3.0 \pm 0.79$ & $4.5 \pm 1.51$ & $2.95 \pm 2.46$ & $17.14 \pm 7.36$ \\
\hline $\mathrm{Mg}$ & $1700.3 \pm 81.7$ & $1.1 \pm 0.56$ & $0.5 \pm 0.44$ & $0.978 \pm 0.38$ & $0.99 \pm 0.50$ & $3.46 \pm 1.23$ \\
\hline $\mathrm{Mn}$ & $301.3 \pm 24.3$ & $3.6 \pm 1.46$ & $21.5 \pm 22.48$ & $3.07 \pm 0.77$ & $3.01 \pm 1.93$ & $43.23 \pm 22.05$ \\
\hline $\mathrm{Ni}$ & $1112.8 \pm 64.8$ & $86.4 \pm 30.98$ & $1669.4 \pm 663.03$ & $52.8 \pm 20.92$ & $64.4 \pm 56.15$ & $2846.74 \pm 703.85$ \\
\hline $\mathrm{Pb}$ & $204.4 \pm 8.7$ & $122.8 \pm 60.00$ & $79.8 \pm 22.97$ & $120.4 \pm 68.91$ & $80.48 \pm 81.19$ & $445.11 \pm 156.22$ \\
\hline $\mathrm{Sr}$ & $57.7 \pm 2.1$ & $7.96 \pm 4.41$ & $3.15 \pm 2.58$ & $7.56 \pm 2.53$ & $6.23 \pm 4.51$ & $23.10 \pm 9.37$ \\
\hline V & $27.95 \pm 2.3$ & $1.84 \pm 0.97$ & $9.7 \pm 10.19$ & $2.2 \pm 1.20$ & $2.8 \pm 2.56$ & $22.50 \pm 12.02$ \\
\hline $\mathrm{Zn}$ & $3591.6 \pm 51.84$ & $796.3 \pm 410.26$ & $283.9 \pm 161.44$ & $652.5 \pm 296.49$ & $560.96 \pm 465.14$ & $2284.92 \pm 932.38$ \\
\hline
\end{tabular}

the relative humidity, especially the concentration of $\mathrm{K}$ $(P<0.01)$. As the relative humidity increases, it not only inhibits the rise of the coarse particles but also helps the atmospheric particles to form a coagulant, promoting precipitation and reducing the concentration in the air. Most of the total metal concentration was positively related to the speed of wind. Generally, the greater the wind speed, the more the wind enhances the diffusion and dilution of the air pollutants. An extended lack of air flow will inhibit pollutant diffusion and increase the pollution in the near-ground layer. A high wind speed can promote the exchange and migration of the atmosphere, but when the wind speed is too great and the climate is
Table 3 Relationship between the total concentrations of the metal and meteorological factors as represented by Pearson's coefficient (r)

\begin{tabular}{|c|c|c|c|c|c|c|c|c|}
\hline & $\mathrm{T}$ & WS & RH & $\mathrm{P}$ & PM20.5 & $\mathrm{SO} 2$ & NOx & $\mathrm{CO}$ \\
\hline $\mathrm{Al}$ & $-0.571 * *$ & -0.479 & -0.334 & 0.216 & $0.150 * *$ & $0.119 * *$ & $0.478 * *$ & $0.634 * *$ \\
\hline As & -0.291 & 0.143 & -0.331 & $0.830 * *$ & 0.012 & 0.037 & 0.139 & 0.252 \\
\hline $\mathrm{Ba}$ & -0.207 & -0.124 & -0.617 & 0.182 & 0.067 & $0.468 * *$ & 0.124 & $0.768 * *$ \\
\hline $\mathrm{Ca}$ & -0.080 & 0.067 & 0.373 & $0.751 * *$ & $0.541 * *$ & $0.478 * *$ & 0.185 & $0.754 * *$ \\
\hline $\mathrm{Cd}$ & $-0.322 * *$ & 0.134 & -0.135 & $0.829 * *$ & 0.214 & $0.389 * *$ & 0.270 & $0.810 * *$ \\
\hline Co & $-0.416^{* *}$ & 0.269 & -0.397 & $0.879 * *$ & 0.280 & 0.159 & $0.412 * *$ & $0.573 * *$ \\
\hline $\mathrm{Cr}$ & $-0.367 * *$ & 0.169 & -0.138 & $0.806^{* *}$ & $0.259 * *$ & $0.440 * *$ & 0.293 & $0.872 * *$ \\
\hline $\mathrm{Cu}$ & $-0.590 * *$ & 0.511 & 0.413 & 0.193 & 0.178 & 0.101 & $0.548 * *$ & $0.687 * *$ \\
\hline $\mathrm{Fe}$ & -0.214 & 0.050 & -0.570 & $0.979 * *$ & $0.350 * *$ & $0.208^{* *}$ & 0.176 & $0.433 * *$ \\
\hline K & $-0.729 * *$ & -0.709 & $-0.840 * *$ & 0.077 & $0.619 * *$ & 0.163 & $0.668 * *$ & $0.548 * *$ \\
\hline $\mathrm{Mg}$ & $0.492 * *$ & -0.453 & -0.781 & 0.086 & $0.357 * *$ & 0.122 & $0.502 * *$ & $0.733 * *$ \\
\hline Mn & -0.142 & 0.036 & -0.420 & $0.761 * *$ & $0.484 * *$ & 0.281 & 0.317 & $0.614 * *$ \\
\hline $\mathrm{Ni}$ & $-0.504 * *$ & 0.307 & -0.179 & $0.867 * *$ & $0.131 * *$ & $0.273 * *$ & $0.364 * *$ & $0.734 * *$ \\
\hline $\mathrm{Pb}$ & -0.161 & 0.011 & -0.374 & $0.865^{* *}$ & $0.373 * *$ & $0.320 * *$ & 0.221 & $0.632 * *$ \\
\hline $\mathrm{Sr}$ & $-0.652 * *$ & -0.580 & -0.553 & 0.242 & 0.278 & 0.060 & $0.671 * *$ & $0.795 * *$ \\
\hline V & -0.172 & 0.055 & -0.733 & $0.937 * *$ & $0.398 * *$ & 0.047 & 0.199 & 0.203 \\
\hline $\mathrm{Zn}$ & 0.286 & -0.127 & -0.184 & 0.281 & 0.166 & $0.532 * *$ & 0.144 & $0.829 * *$ \\
\hline
\end{tabular}

**Correlation is significant at $P=0.01$ (2-tailed). * Correlation is significant at $P=0.05$ level (two-tailed). $R H$, relative humidity; $P$, pressure; $T$, temperature; $W S$, wind speed 
dry, it will lift sand into the air, aggravating the pollution. Our study confirms this outcome.

\section{Sources of metal and the enrichment factor}

The average EF values for different elements on every sampling date are shown in Table 2. The EF average values for $\mathrm{K}$, $\mathrm{Ca}, \mathrm{Fe}, \mathrm{Mg}, \mathrm{Sr}$, and $\mathrm{V}$ were lower than 10 , indicating no enrichment of these metals, and that they originated mainly from sources in nature, such as in soil materials blown into the atmosphere and rocks undergoing natural weathering. The EF average values of $\mathrm{Cr}, \mathrm{Co}, \mathrm{Cu}$, and $\mathrm{Ni}$ were between 10 and 100 , indicating a moderate enrichment for these metals. The EF values for the remaining metal elements exceeded 100, indicating the significant enrichment of these metals. The metal with the highest $\mathrm{EF}$ value in this study was $\mathrm{Cr}$ (its average $\mathrm{EF}$ was 2517). In addition, a logarithmic diagram of the enrichment factors (Fig. 2) was made to visualize the relationship between the different particle diameters and the enrichment of the elements in an intuitive way. It can be seen that between the boundaries 1 and 2, the source of some of the particle sizes was the result of the combined action of an anthropogenic source and natural source. Particles with a diameter of $0.1-0.5 \mu \mathrm{m}$ were strongly enriched with $\mathrm{Cr}$, $\mathrm{Co}$, and Ni. The enrichment factor of $\mathrm{Zn}$ and $\mathrm{Cu}$ was basically the same at different particle diameters, while $\mathrm{Cd}$ and $\mathrm{Pb}$ were mainly concentrated in the particle diameter range of $d_{p}<$ $1 \mu \mathrm{m}$. Overall, the smaller the particle diameter was, the higher the possibility that the element originated from natural sources. When the element originated from both natural and anthropogenic sources, the particles $(\mathrm{d}<0.1 \mu \mathrm{m})$ had a high EF. When the element was strongly enriched, the particles with a diameter of $0.1-0.5 \mu \mathrm{m}$ predominated.

Scholars have made some achievements in the apportionment of atmospheric particulates in the sources of heavy metals. Coal fly ash, industrial emissions, exhaust emissions, metal smelting plants, the ceramic industry, the mining industry, waste incineration (Duan and Tan 2013), energy power stations, the cement industry, and transportation are sources of atmospheric particles with metal (Lahd Geagea et al. 2008). Table 3 shows that the concentrations of most elements correlate positively with $\mathrm{NO}_{2}$, $\mathrm{CO}$, and $\mathrm{SO}_{2}$ emissions, which are mainly the result of coal combustion.

\section{Chemical partitioning of metals bound to fine particles}

The concentrations and chemical partitioning of the studied metals in the four fractions are presented in Fig. 3. Geochemical elements $(\mathrm{EF}<10)$ like $\mathrm{K}, \mathrm{Ca}, \mathrm{Sr}$, and $\mathrm{V}$ existed mainly in the $\mathrm{F} 1$ part. $\mathrm{Mg}$ and $\mathrm{Fe}$ were mainly found in the fraction $\mathrm{F} 4$, with the average shares of $41.6 \%$ and $34.9 \%$, respectively. In addition, the soluble and exchangeable fractions (F1) of $\mathrm{As}, \mathrm{Cd}$, and $\mathrm{Pb}$ exceeded those of other metals, over $50 \%$, while the average share of the same three elements in F4 was very low. As was present in a relatively high proportion of $93.38 \%$ in the first three fractions. $\mathrm{Cr}, \mathrm{Co}$, and $\mathrm{Ni}$ were present in the last three fractions in relatively high proportions of $99.32 \%, 93.75 \%$, and $94.5 \%$, respectively. Cr, Co, Mn, and $\mathrm{Ni}$ were predominantly present in fraction $\mathrm{F} 4$.

As shown in Fig. 3, Fe and $\mathrm{Mg}$ originated from natural sources $(E F<10)$ and their F1 to F4 ratio was high, indicating that the F1 and F4 fractions contributed significantly to the environmental behaviors of the metals. The EF $(10-100)$ was in $\mathrm{Cr}, \mathrm{Ni}, \mathrm{Co}, \mathrm{Cu}$, and $\mathrm{Pb}$, and the ratio of $\mathrm{F} 1$ in $\mathrm{Pb}$ was high. Ba was mostly present in the $\mathrm{F} 3$ fraction, while the ratio of $\mathrm{F} 1$ and $\mathrm{F} 4$ was high for $\mathrm{K}, \mathrm{Ca}$, and $\mathrm{V}$. Fe and $\mathrm{Mn}$ were present predominantly in the $\mathrm{F} 4$ fraction, and $\mathrm{Sr}$ was found mainly in the $\mathrm{F} 1$ fraction. The values of $\mathrm{EF}$ of $\mathrm{As}, \mathrm{Cd}, \mathrm{Co}, \mathrm{Cr}, \mathrm{Ni}, \mathrm{Pb}$, and $\mathrm{Zn}$ exceeded
Fig. 2 A logarithmic diagram of the enrichment factors

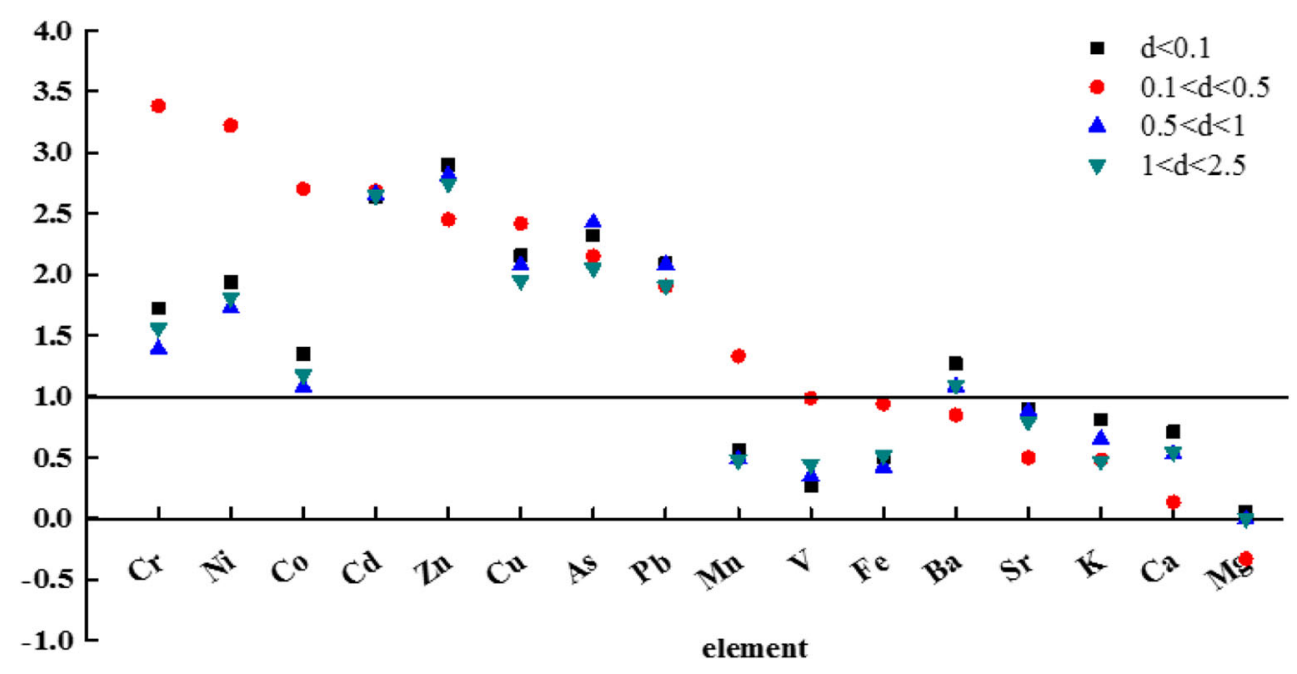


Fig. $3 \mathrm{PM}_{2.5}$ metal chemical partitioning. Metal chemical partitioning at different particle diameters and during the sampling period
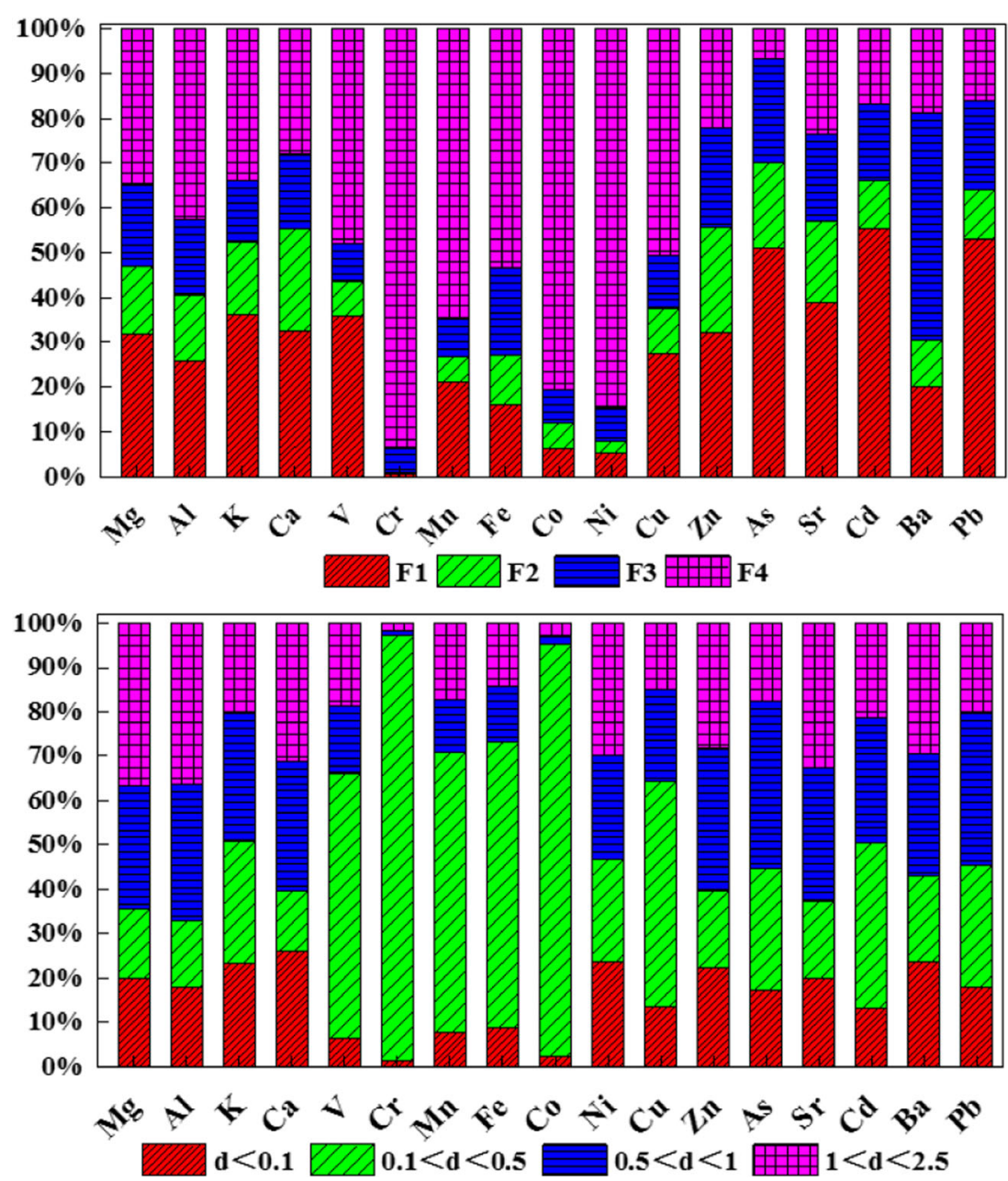

100, indicating a significant enrichment. As, $\mathrm{Cd}$, and $\mathrm{Pb}$ predominated in the $\mathrm{F} 1$ fraction, while $\mathrm{Ni}, \mathrm{Co}$, and $\mathrm{Cr}$ predominated in the $\mathrm{F} 4$ fraction. The ratio of $\mathrm{F} 1$ to $\mathrm{F} 4$ was high for $\mathrm{Zn}$. In conclusion, F1 and F4 were the key fractions, containing relatively enriched and highly enriched elements. Figure 3 shows that metals $\mathrm{V}, \mathrm{Cr}$, $\mathrm{Mn}, \mathrm{Fe}, \mathrm{Co}$, and $\mathrm{Ca}$ were mainly found with particle sizes of $0.1-0.5 \mu \mathrm{m}$. The other elements were distributed uniformly in 4 particle sizes.

\section{Bio-accessibility of metals in $\mathrm{PM}_{2.5}$}

The proportion of F1 can be used to study the bioactivity of various metals ( $\mathrm{Li}$ et al. 2017). We divided the particle sizes into four levels to evaluate the potential bioactivity risk of the different metals.

The percentages of F1 and bio-accessibility during the sampling period are shown in Fig. 4. We found that As, Cd, and $\mathrm{Cr}$ metals had the highest potential biological activity. The highest average proportion of $\mathrm{Cd}, 57 \%$, was present in the $\mathrm{F} 1$ fraction when the particle diameter was $d_{p}<0.1 \mu \mathrm{m}$. The highest average proportions of As with particle diameters of
$0.1-0.5 \mu \mathrm{m}$ and $0.5-1 \mu \mathrm{m}$ in the F1 fraction were $18.2 \%$ and $59.8 \%$, respectively. The highest average proportion of $\mathrm{Cr}$ in F1 was $61.6 \%$ when the particle diameter was $1-2.5 \mu \mathrm{m}$, while the $\mathrm{F} 1$ of $\mathrm{Cr}$ with $\mathrm{d}_{\mathrm{p}}<2.5 \mu \mathrm{m}$ was almost 0 . We found that $\mathrm{Cu}, \mathrm{Pb}$, and $\mathrm{V}$ with $\mathrm{d}_{\mathrm{p}}<0.1 \mu \mathrm{m}, \mathrm{Fe}$ with $\mathrm{d}_{\mathrm{p}} 1-2.5 \mu \mathrm{m}, \mathrm{K}$ in each size, except $d_{p} 0.5-1 \mu \mathrm{m}$, and $\mathrm{Zn}$ with $0.1-0.5 \mu \mathrm{m}$ had a relatively strong bio-accessible risk. Finally, $\mathrm{Cr}, \mathrm{Co}, \mathrm{Cd}, \mathrm{Cu}$, $\mathrm{Fe}, \mathrm{Pb}, \mathrm{K}, \mathrm{V}$, and $\mathrm{Ni}$ posed a low bio-accessible risk in particles with a diameter of $0.1-0.5 \mu \mathrm{m}$.

The F1 proportion of $\mathrm{Mg}$, Sr, and $\mathrm{Zn}$ with different particle diameters was at a low potential risk level, but when the concentration of $\mathrm{d}_{\mathrm{p}}<2.5 \mu \mathrm{m}$ exceeded the original basis, it rose to a strong risk level, indicating that the potential risk was not stronger when the particle size was small. Similarly, we found that the potential risk of some metals, such as $\mathrm{Co}, \mathrm{Fe}$, and $\mathrm{Ba}$, dropped suddenly at $\mathrm{d}_{\mathrm{p}}<2.5 \mu \mathrm{m}$. Therefore, we speculated about the chemical properties of each metal and determined that the potential risks vary at different particle diameters.

There is some inconsistency in regard to suitable solvents used for determining the accessibility of metals to organisms. Pure water can act as a useful agent for leaching, and it is used for the calculation of PM in metal biodegradable points 
Fig. 4 Percentage of F1 and bioactivity found during the sampling period

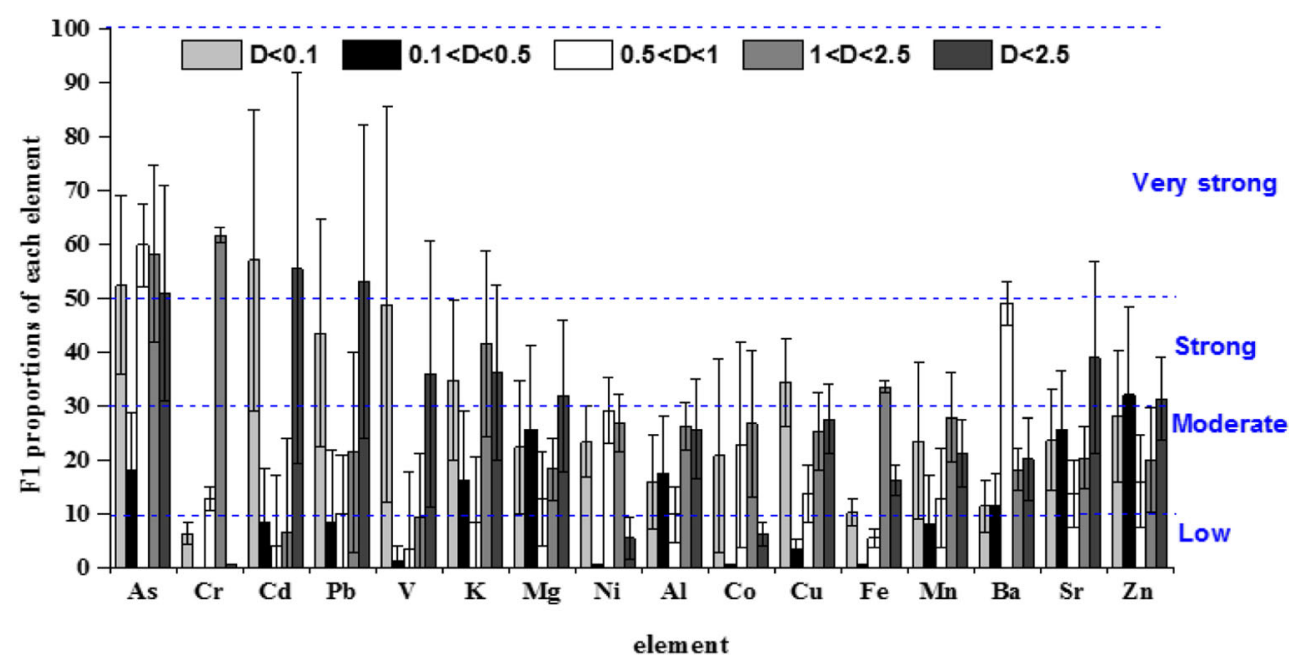

(Mukhtar and Limbeck 2013). Table 4 compares the results of this study with those of other studies. The F1 fractions of
$\mathrm{PM}_{2.5}$ generally vary among different cities, which may be due to the composition of $\mathrm{PM}_{2.5}$, sampling period, and different

Table 4 Comparison of the percentage of F1 in $\mathrm{PM}_{2.5}$ using water as a leaching agent and the associated references

\begin{tabular}{|c|c|c|c|c|c|c|c|}
\hline & $\begin{array}{l}\text { Schleicher et al. } \\
\text { (2011) }\end{array}$ & $\begin{array}{l}\text { Falta et al. } \\
(2008)\end{array}$ & $\begin{array}{l}\text { von Schneidemesser et al. } \\
\text { (2010) }\end{array}$ & $\begin{array}{l}\text { Feng et al. } \\
(2009)\end{array}$ & $\begin{array}{l}\text { Li et al. } \\
(2017)\end{array}$ & $\begin{array}{l}\text { Heal et al. } \\
(2005)\end{array}$ & $\begin{array}{l}\text { This study } \\
\text { (2017) }\end{array}$ \\
\hline Sampling site & Beijing, China & $\begin{array}{l}\text { Vienna, } \\
\text { Austria }\end{array}$ & Lahore, Pakistan & $\begin{array}{l}\text { Guangzhou, } \\
\text { China }\end{array}$ & $\begin{array}{r}\text { Nanjing, } \\
\text { China }\end{array}$ & $\begin{array}{l}\text { Edinburgh, } \\
\text { UK }\end{array}$ & $\begin{array}{l}\text { Dongguan, } \\
\text { China }\end{array}$ \\
\hline $\begin{array}{l}\text { Extraction time } \\
\qquad(\mathrm{min})\end{array}$ & 180 & 120 & $?$ & 180 & 180 & 60 & 960 \\
\hline $\mathrm{T}\left({ }^{\circ} \mathrm{C}\right)$ & RT & & RT & RT & RT & RT & RT \\
\hline Particle & $\mathrm{PM}_{2.5}$ & $\mathrm{PM}_{2.5}$ & $\mathrm{PM}_{2.5}$ & $\mathrm{PM}_{2.5}$ & $\mathrm{PM}_{2.5}$ & $\mathrm{PM}_{2.5}$ & $\mathrm{PM}_{2.5}$ \\
\hline Unit & $\%$ & $\%$ & $\%$ & $\%$ & $\%$ & $\%$ & $\%$ \\
\hline $\mathrm{Al}$ & 8 & & $1.5 \pm 1.0$ & 1.5 & $9.1 \pm 3.4$ & & 51.9 \\
\hline As & 52 & & $36 \pm 23$ & 32.6 & $35 \pm 8.1$ & 64 & 84.8 \\
\hline $\mathrm{Ba}$ & & & $30 \pm 9.6$ & & $36 \pm 7.8$ & & 54.8 \\
\hline $\mathrm{Ca}$ & 27 & & $76 \pm 15$ & & $50 \pm 9.5$ & & 55.7 \\
\hline $\mathrm{Cd}$ & 34 & 86 & $73 \pm 17$ & 39.7 & $46 \pm 6.8$ & 75 & 89.9 \\
\hline $\mathrm{Co}$ & 40 & 44 & $22 \pm 5.7$ & 26.8 & $17 \pm 7.5$ & & 54.22 \\
\hline $\mathrm{Cr}$ & 28 & 18 & $9.6 \pm 6.6$ & 6.6 & $35 \pm 7.7$ & 28 & 65.98 \\
\hline $\mathrm{Cu}$ & 17 & 78 & $13 \pm 8.4$ & 20.1 & $37 \pm 10$ & 50 & 59.61 \\
\hline $\mathrm{Fe}$ & 7 & & $1.8 \pm 1.3$ & 1.7 & $11 \pm 5.0$ & 10 & 57.84 \\
\hline $\mathrm{K}$ & 54 & & $67 \pm 15$ & & $62 \pm 13$ & & 47.57 \\
\hline $\mathrm{Mg}$ & 38 & & $22 \pm 5.7$ & & $45 \pm 7.5$ & & 58.20 \\
\hline $\mathrm{Mn}$ & 44 & 56 & $37 \pm 9.4$ & 30.3 & $38 \pm 7.9$ & 45 & 38.50 \\
\hline Mo & & 44 & $37 \pm 8.5$ & 45.2 & $54 \pm 13$ & & \\
\hline $\mathrm{Na}$ & & & $79 \pm 10$ & & $59 \pm 7.7$ & & \\
\hline $\mathrm{Ni}$ & 4 & 64 & $38 \pm 19$ & 27.6 & $29 \pm 8.4$ & 45 & 88.08 \\
\hline $\mathrm{Pb}$ & 20 & 82 & $23 \pm 16$ & 12.2 & $28 \pm 5.9$ & 50 & 56.52 \\
\hline $\mathrm{Sr}$ & 20 & & $65 \pm 13$ & & $56 \pm 8.0$ & & \\
\hline $\mathrm{Ti}$ & 2 & 2 & $0.3 \pm 0.2$ & & $3.5 \pm 2.5$ & 14 & \\
\hline V & 21 & & $19 \pm 15$ & & $29 \pm 11$ & 80 & 74.40 \\
\hline $\mathrm{Zn}$ & 20 & 74 & $65 \pm 22$ & 46.3 & $54 \pm 8.8$ & 75 & 71.47 \\
\hline
\end{tabular}




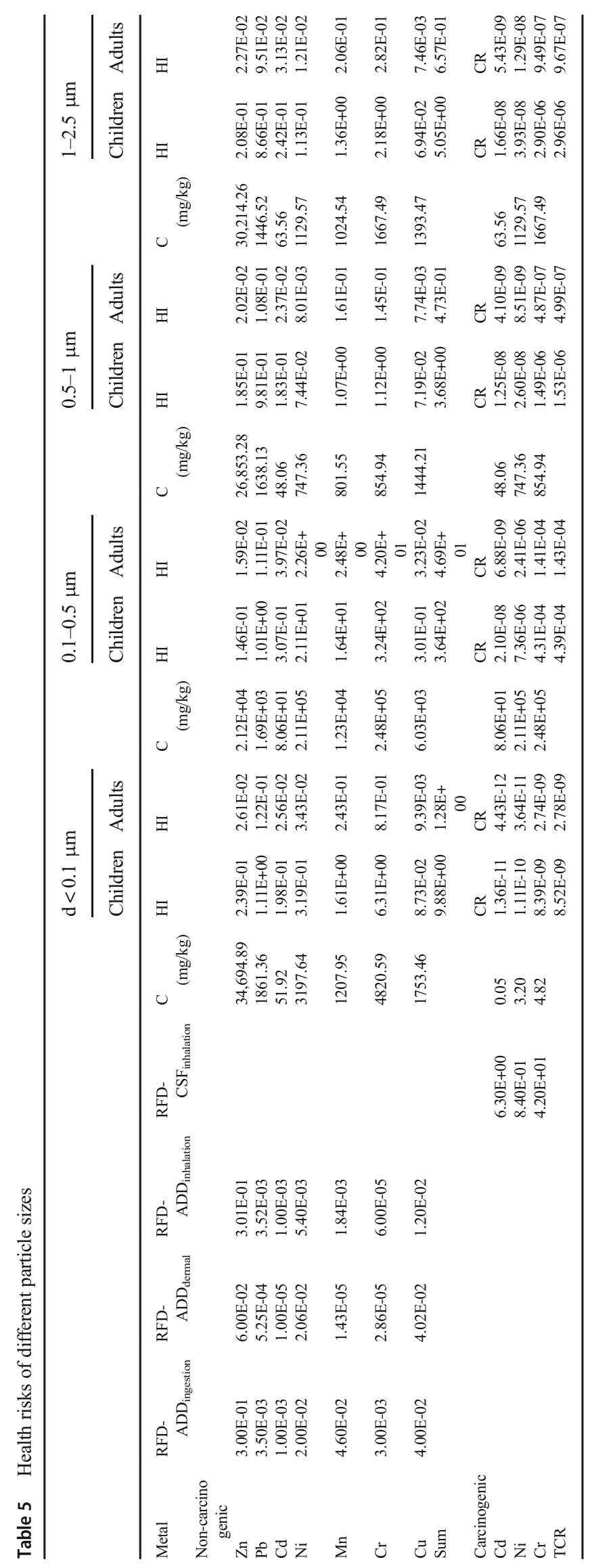


sources of metals in the air. Among the cities studied, the highest average share of $\mathrm{Cd}$ in $\mathrm{F} 1$ was found in Dongguan city. $\mathrm{Al}$ and $\mathrm{Fe}$ were found in lower $\mathrm{F} 1$ proportions of other cities.

\section{Health risk assessment}

The health risk of inhalation was analyzed for an assessment of the adverse effects of airborne metal exposure. As shown in Table 5, the values of non-carcinogenic risk for adults resulting from inhaling atmospheric particles containing $\mathrm{Cd}, \mathrm{Cr}, \mathrm{Cu}, \mathrm{Mn}, \mathrm{Ni}, \mathrm{Pb}$, and $\mathrm{Zn}$ were lower than the safety limit $(\mathrm{HI}<1)$, while adults $(4.69 \mathrm{E}+01)$ and children $(3.64 \mathrm{E}+02)$ had the greatest risk of noncarcinogenesis by inhaling atmospheric particles $(0.5$ $2.5 \mu \mathrm{m}$ ). In addition, the concentrations of the metals $\mathrm{Cr}, \mathrm{Mn}, \mathrm{Ni}$, and $\mathrm{Pb}$ contributed significantly to the noncarcinogenic risks, illustrating that the concentrations of these toxic metals exceed safety levels. Overall, the noncarcinogenic hazard index (HI) of atmospheric particulate matter in Dongguan city exceeded 1, indicating that there, the residents were experiencing obvious non-carcinogenic risk; the government needs to take measures to control the quality of the air.

In the assessment of carcinogenic risk, a value of the carcinogenic risk between $1 \mathrm{E}-06$ and 1E-04 indicated an acceptable risk of carcinogenesis, 1E-04 indicated a high carcinogenic risk environment, and 1E-06 represented a precautionary criterion. The carcinogenic risks of inhalation of $\mathrm{Cd}, \mathrm{Cr}$, and $\mathrm{Ni}\left(\mathrm{d}_{\mathrm{p}}<0.1 \mu \mathrm{m}\right)$ from the air were lower than the children's precautionary criterion $\left(10^{-6}\right)$, indicating that the amount of heavy metals contained in the atmospheric particles at this level was not enough to cause carcinogenic risk. The risk of carcinogenesis for children from inhaling atmospheric particulate matter $(0.5-2.5 \mu \mathrm{m})$ just exceeded the warning line $\left(10^{-6}\right)$, while that of adults did not exceed the warning line, suggesting that children inhaling heavy metal particles in the two grade particles can cause a slight risk of carcinogenesis. However, when adults (4.39E-04) and children (1.43E-04) inhaled airborne particles $(0.1-0.5 \mu \mathrm{m})$ containing heavy metals, the carcinogenesis risk was higher than the risk value $\left(10^{-4}\right)$, indicating a strong carcinogenic effect.

Overall, the health risk assessment of different particle sizes was analyzed, and we found that the hazard index (HI) and the total carcinogenic risk (TCR) were far beyond the safety threshold when the size of the particle size was $0.1-0.5 \mu \mathrm{m}$. The degree of heavy metals contained in other particle sizes $(\mathrm{d}<0.1 \mu \mathrm{m}, 0.5-1 \mu \mathrm{m}$, and $1-2.5 \mu \mathrm{m})$ was generally beyond the safety threshold. Therefore, the air quality in Dongguan was considered to be in a risk state. Children were at more non-carcinogenic and carcinogenic risk than adults during the winter season of 2016-2017.

\section{Summary}

In this study, we analyzed urban atmospheric environmental particles with different diameters in the Dongguan area. We collected atmospheric fine particles in winter and analyzed the partitioning of the particle-bound metals and the sources of metals in the particulate matter and their biotoxic effects. We then assessed their non-carcinogenic and carcinogenic health risks. When we studied the concentration of the total metals in the atmospheric particulates, we found that the F1 and F4 components in the atmospheric particulates were indicators. When these two components increase, the concentrations of metals bound to atmospheric fine particles are more abundant, indicating that human pollution is the main cause. Elements such as $\mathrm{As}, \mathrm{Ba}, \mathrm{Cd}, \mathrm{Mg}$, and $\mathrm{Pb}$ show relatively high proportions in the F1 fraction and strong potentials for the bioaccessibilities of many metal fractions in the atmosphere, and appear to be enhanced by high temperatures and humidity. $\mathrm{Mn}$ and $\mathrm{Cr}$ showed the highest $\mathrm{HQ}$ values and had the highest carcinogenic-associated risk for both children and adults. The risk index (HI) and the carcinogenic risk (TCR) were far beyond the safety threshold when the particle size was $0.1-$ $0.5 \mu \mathrm{m}$. Our results indicate that the residents in Dongguan city are experiencing obvious non-carcinogenic and carcinogenic risks.

Acknowledgments We thank LetPub (www.letpub.com) for its linguistic assistance during the preparation of this manuscript.

Funding Support for this study was graciously provided by the Key Laboratory of Atmospheric Compound Pollution Research and the Second Base of Science Research Institute of Metrology in Guangdong.

\section{Compliance with ethical standards}

Conflict of interest The authors declare that they have no conflict of interest.

Open Access This article is distributed under the terms of the Creative Commons Attribution 4.0 International License (http:// creativecommons.org/licenses/by/4.0/), which permits unrestricted use, distribution, and reproduction in any medium, provided you give appropriate credit to the original author(s) and the source, provide a link to the Creative Commons license, and indicate if changes were made.

\section{References}

Arain MB, Kazi TG, Jamali MK, Afridi HI, Jalbani N, Sarfraz RA, Baig JA, Kandhro GA, Memon MA (2008) Time saving modified BCR sequential extraction procedure for the fraction of $\mathrm{Cd}, \mathrm{Cr}, \mathrm{Cu}, \mathrm{Ni}, \mathrm{Pb}$ and $\mathrm{Zn}$ in sediment samples of polluted lake. J Hazard Mater 160: 235-239. https://doi.org/10.1016/j.jhazmat.2008.02.092

Ballester F (2001) Air pollution and emergency hospital admissions for cardiovascular diseases in Valencia, Spain. J Epidemiol Community Health 55:57-65. https://doi.org/10.1136/jech.55.1.57 
Betha R, Behera SN, Balasubramanian R (2014) 2013 Southeast Asian smoke haze: fractionation of particulate-bound elements and associated health risk. Environ Sci Technol 48:4327-4335. https://doi. org/10.1021/es405533d

Chen J, Tan M, Li Y, Zheng J, Zhang Y, Shan Z, Zhang G, Li Y (2008) Characteristics of trace elements and lead isotope ratios in PM2.5 from four sites in Shanghai. J Hazard Mater 156:36-43. https://doi. org/10.1016/j.jhazmat.2007.11.122

CNEMC (China National Environmental Monitoring Center) (1990) Background values of soil elements in China. China Environmental Science Press, Beijing (in Chinese)

Davidson CM, Urquhart GJ, Ajmone-Marsan F, Biasioli M, da Costa Duarte A, Díaz-Barrientos E, Grčman H, Hossack I, Hursthouse AS, Madrid L, Rodrigues S, Zupan M (2006) Fractionation of potentially toxic elements in urban soils from five European cities by means of a harmonised sequential extraction procedure. Anal Chim Acta 565:63-72. https://doi.org/10.1016/j.aca.2006.02.014

Donaldson K, Brown D, Clouter A, Duffin R, MacNee W, Renwick L, Tran L, Stone V (2002) The pulmonary toxicology of ultrafine particles. J Aerosol Med 15:213-220. https://doi.org/10.1089/ 089426802320282338

Duan J, Tan J (2013) Atmospheric heavy metals and arsenic in China: situation, sources and control policies. Atmos Environ 74:93-101. https://doi.org/10.1016/j.atmosenv.2013.03.031

Falta T, Limbeck A, Koellensperger G, Hann S (2008) Bioaccessibility of selected trace metals in urban PM2.5 and PM10 samples: a model study. Anal Bioanal Chem 390:1149-1157. https://doi.org/10.1007/ s00216-007-1762-5

Feng XD, Dang Z, Huang WL, Yang C (2009) Chemical speciation of fine particle bound trace metals. Int J Environ Sci Technol (Tehran) 6:337-346. https://doi.org/10.1007/bf03326071

Heal MR, Hibbs LR, Agius RM, Beverland IJ (2005) Total and watersoluble trace metal content of urban background PM10, PM2.5 and black smoke in Edinburgh, UK. Atmos Environ 39:1417-1430. https://doi.org/10.1016/j.atmosenv.2004.11.026

Hsu CY, Chiang HC, Lin SL, Chen MJ, Lin TY, Chen YC (2016) Elemental characterization and source apportionment of PM 10 and PM 2.5 in the western coastal area of central Taiwan. Sci Total Environ 541:1139-1150. https://doi.org/10.1016/j.scitotenv.2015. 09.122

Hu X, Zhang Y, Ding Z, Wang T, Lian H, Sun Y, Wu J (2012) Bioaccessibility and health risk of arsenic and heavy metals $(\mathrm{Cd}$, $\mathrm{Co}, \mathrm{Cr}, \mathrm{Cu}, \mathrm{Ni}, \mathrm{Pb}, \mathrm{Zn}$ and $\mathrm{Mn}$ ) in TSP and PM2.5 in Nanjing, China. Atmos Environ 57:146-152. https://doi.org/10.1016/j. atmosenv.2012.04.056

Kang H, Zhu B, Su J, Wang H, Zhang Q, Wang F (2013) Analysis of a long-lasting haze episode in Nanjing, China. Atmos Res 120-121: 78-87. https://doi.org/10.1016/j.atmosres.2012.08.004

Lahd Geagea M, Stille P, Gauthier-Lafaye F, Millet M (2008) Tracing of industrial aerosol sources in an urban environment using $\mathrm{Pb}, \mathrm{Sr}$, and Nd isotopes. Environ Sci Technol 42:692-698. https://doi.org/10. $1021 / \mathrm{es} 071704 \mathrm{c}$

Lewis TC, Robins TG, Dvonch JT, Keeler GJ, Yip FY, Mentz GB, Lin X, Parker EA, Israel BA, Gonzalez L, Hill Y (2005) Air pollutionassociated changes in lung function among asthmatic children in Detroit. Environ Health Perspect 113:1068-1075. https://oi.org/ 10.1289/ehp. 7533

Li H, Qian X, Hu W, Wang Y, Gao H (2013a) Chemical speciation and human health risk of trace metals in urban street dusts from a metropolitan city, Nanjing, SE China. Sci Total Environ 456-457:212221. https://doi.org/10.1016/j.scitotenv.2013.03.094

Li H, Qian X, Wang Q (2013b) Heavy metals in atmospheric particulate matter: a comprehensive understanding is needed for monitoring and risk mitigation. Environ Sci Technol 47:13210-13211. https:// doi.org/10.1021/es404751a

Li H, Wu H, Wang Q', Yang M, Li F, Sun Y, Qian X, Wang J, Wang C (2017) Chemical partitioning of fine particle-bound metals on hazefog and non-haze-fog days in Nanjing, China and its contribution to human health risks. Atmos Res 183:142-150. https://doi.org/10. 1016/j.atmosres.2016.07.016

Mukhtar A, Limbeck A (2013) Recent developments in assessment of bio-accessible trace metal fractions in airborne particulate matter: a review. Anal Chim Acta 774:11-25. https://doi.org/10.1016/j.aca. 2013.02.008

Ostro B, Broadwin R, Green S, Feng WY, Lipsett M (2006) Fine particulate air pollution and mortality in nine California counties: results from CALFINE. Environ Health Perspect 114:29-33. https://doi. org/10.1289/ehp. 8335

Pérez G, López-Mesas M, Valiente M (2008) Assessment of heavy metals remobilization by fractionation: comparison of leaching tests applied to roadside sediments. Environ Sci Technol 42:2309-2315. https://doi.org/10.1021/es0712975

Pope CA III, Burnett RT, Thun MJ, Calle EE, Krewski D, Ito K, Thurston GD (2002) Lung cancer, cardiopulmonary mortality, and long-term exposure to fine particulate air pollution. JAMA 287:1132-1141. https://doi.org/10.1001/jama.287.9.1132

Samoli E, Analitis A, Touloumi G, Schwartz J, Anderson HR, Sunyer J, Bisanti L, Zmirou D, Vonk JM, Pekkanen J, Goodman P, Paldy A, Schindler C, Katsouyanni K (2005) Estimating the exposureresponse relationships between particulate matter and mortality within the APHEA multicity project. Environ Health Perspect 113: 88-95. https://doi.org/10.1289/ehp.7387

Schleicher NJ, Norra S, Chai F, Chen Y, Wang S, Cen K, Yu Y, Stüben D (2011) Temporal variability of trace metal mobility of urban particulate matter from Beijing - a contribution to health impact assessments of aerosols. Atmos Environ 45:7248-7265. https://doi.org/10. 1016/j.atmosenv.2011.08.067

Shao L, Yang S, Shi Z, Lv S (2006) Physicochemical characteristics and bioactivity of inhalable particulates in urban atmosphere. China Meteorological Press, Beijing (in Chinese)

US EPA (U.S. Environmental Protection Agency) (2011) Risk assessment guidance for superfund, volume I: part A: human health evaluation manual; part E: supplemental guidance for dermal risk assessment; part F: supplemental guidance for inhalation risk assessment. U.S. Environmental Protection Agency, Washington, D.C

von Schneidemesser E, Stone EA, Quraishi TA, Shafer MM, Schauer JJ (2010) Toxic metals in the atmosphere in Lahore, Pakistan. Sci Total Environ 408:1640-1648. https://doi.org/10.1016/j.scitotenv.2009. 12.022

Xie M, Hannigan MP, Dutton SJ, Milford JB, Hemann JG, Miller SL, Schauer JJ, Peel JL, Vedal S (2012) Positive matrix factorization of PM2.5: comparison and implications of using different speciation data sets. Environ Sci Technol 46:11962-11970. https://doi.org/10. $1021 / \mathrm{es} 302358 \mathrm{~g}$

Yang F, Chen H, Du J, Yang X, Gao S, Chen J, Geng F (2012) Evolution of the mixing state of fine aerosols during haze events in Shanghai. Atmos Res 104-105:193-201. https://doi.org/10.1016/j.atmosres. 2011.10.005

Yuan X, Huang H, Zeng G, Li H, Wang J, Zhou C, Zhu H, Pei X, Liu Z, Liu Z (2011) Total concentrations and chemical speciation of heavy metals in liquefaction residues of sewage sludge. Bioresour Technol 102:4104-4110. https://doi.org/10.1016/j.biortech.2010.12.055

Publisher's note Springer Nature remains neutral with regard to jurisdictional claims in published maps and institutional affiliations. 